\title{
Characterization of Eucalyptus Lignin Fractionation from a MIBK- Based Solvothermal Process
}

\author{
Punjarat Khongchamnan ${ }^{1}$, Nopparat Suriyachai ${ }^{1,2}$, \\ Torpong Kreetachat ${ }^{1,2}$ and Saksit Imman ${ }^{1,2, *}$ \\ ${ }^{1}$ School of Energy and Environment, University of Phayao, Phayao 56000, Thailand \\ ${ }^{2}$ Intregated Biorefinery Excellent Center, School of Energy and Environment, University of Phayao, \\ Phayao 56000, Thailand
}

('Corresponding author's e-mail: saksit.im@up.ac.th)

Received: 2 October 2020, Revised: 21 May 2021, Accepted: 30 May 2021

\begin{abstract}
In this study, the effects of sulfuric acid on cellulose yield, lignin removal, and lignin recovery in solvothermal fractionation of eucalyptus (EC) were studied. An acid concentration of $0.04 \mathrm{M}$ sulfuric acid $\left(\mathrm{H}_{2} \mathrm{SO}_{4}\right)$, temperature of $180{ }^{\circ} \mathrm{C}$ and residence time of $30 \mathrm{~min}$ resulted in maximum lignin removal from the solid phase, at $87.7 \%$. Lignin recovery in the organic phase under optimum conditions was $84.6 \%$. It should be noted that $\mathrm{H}_{2} \mathrm{SO}_{4}$ was the best catalyst in the optimal solvothermal process, and it increased the cellulose yield to $95.2 \%$ in the solid phase. Additionally, the physicochemical and structural properties of the extracted lignin were analyzed using FTIR, TGA, elemental analysis, GPC, and Py-GCMS methods. Thermal degradation analysis showed that recovered lignin is primarily composed of syringyl, guaiacyl and p-hydroxyphenyl units cross-linked by $\mathrm{C}-\mathrm{C}$, inter-unit $\alpha-\mathrm{O}-4, \beta-\mathrm{O}-4$ linkages. The weight average molecular weight $(\mathrm{Mw})$ analysis of recovered lignin demonstrated a low molecular weight for recovered lignin $(2.19 \mathrm{~g} / \mathrm{mol})$. However, the main phenolic derivatives in the extracted lignin obtained from EC were S-units (i.e., syringol, 4-methylsyringol, 4-vinylsyringol). In addition, G-units (4-vinylguaiacol, 4methylguaiacol, phenol, 2-methylphenol, and 4-methylphenol) were obtained after release from H-units. Py-GCMS analysis showed the predominance of G-units $(32.8 \%)$ over S-units $(57.4 \%)$. This work demonstrated the potential of fractionated lignin in the production of valuable chemicals in biorefineries.
\end{abstract}

Keywords: Eucalyptus, Biomass material, Lignin fractionation, Solvothermal process, Optimization

\section{Introduction}

Owing to its ready availability, biomass is a promising bioresource in that it can be converted into biomaterials, biofuels, and biochemicals [1]. Generally, biomass materials from agricultural waste residues or economic crops consist mainly of 35 - $50 \%$ cellulose, 20 - 35\% hemicellulose, and $10-25 \%$ lignin [2]. Typically, the chemical content of lignin is of the softwood type (24-33\%), hardwood type $(19-28 \%)$, and grass type $(15-25 \%)$. In terms of structure, lignin can comprise a 3-dimensional amorphous polymer and an amorphous aromatic polymer. The natural structure of lignin consists of aliphatic and aromatic hydroxyl groups and 3 basic phenylpropanoid monomers, such as the p-coumaryl alcohol unit, coniferyl alcohol unit, and sinapyl alcohol unit [3]. In addition, the structure of lignin has various cross-links, including those involving aryglycerol- $\beta$-ether dimer $(\beta-\mathrm{O}-4)$, aryglycerol- $\alpha$-ether dimer $(\alpha-\mathrm{O}-4)$, siaryl ether (4-O-5), resinol $(\beta-5)$, diphenylethane $(\beta-1)$, phenylcoumaran $\left(\beta-\beta^{\prime}\right)$, phenylcoumaran $(\beta-\beta)$, and biphenyl (5-5) [4].

Some lignin content is converted into different value-added products, such as phenol, aromatic sources, and vanillin. Moreover, most phenolic compounds can be produced via lignin extraction from biomass materials. In addition, phenolic compounds can also be used as precursors for the plastic, bioplastic, and phenol-formaldehyde production processes in the chemical and petrochemical industries [5]. The previously studied organosolv fractionation process was selected to fractionate eucalyptus (EC) wood chips with the ternary phase solvent mixture containing methyl isobutyl ketone $(\mathrm{MIBK}) /$ methanol/water $(25: 42: 33 \mathrm{v} / \mathrm{v} \%)$ with $0.008 \mathrm{M}$ sulfuric acid $\left(\mathrm{H}_{2} \mathrm{SO}_{4}\right)$ promoter at $180{ }^{\circ} \mathrm{C}$ for 60 min [6]. The results showed that a lignin solubility in the organic fraction of up to $218 \%$ was obtained, along with a high purity of $92 \%$ [7]. Lignin fractionation by the organosolv fractionation process from 
bagasse, pararubber wood sawdust, palm fiber, and cassava fiber was studied. Under optimal conditions, the solvent mixture consisted of methyl isobutyl ketone:ethanol:water $(0.25: 0.42: 0.33 \mathrm{v} / \mathrm{v} \%)$. It should be noted that an $\mathrm{H}_{2} \mathrm{SO}_{4}$ concentration of $0.025 \mathrm{M}$ showed the highest $(89.8 \%$ ) lignin recovery in the organic phase, and a $16.9 \%$ fraction of a phenolic compound was identified through Py-GCMS. Moreover, the highest lignin removal efficiencies, 88.2, 67.3 and $71.7 \%$, were found for bagasse, pararubber wood sawdust, palm fiber and cassava fiber, respectively.

This research is designed to isolate lignin from fractionation of EC using a solvothermal fractionation-based organosolv process under optimal conditions. Moreover, solid residue and isolated lignin were characterized using different techniques. Characterization techniques used to investigate the basic structure and physicochemical and thermal decomposition properties included Fourier transform infrared spectrophotometry (FTIR), thermogravimetric analysis (TGA), elemental analysis (CHONS), gel permeation chromatography (GPC), X-ray diffraction analysis (XRD, scanning electron microscopy (SEM), and pyrolysis gas chromatography-mass spectrometry (Py-GCMS); the results were used for qualitative and quantitative analyses of lignin recovery, and the properties were compared to those of commercial lignin under stable conditions. In this work, we focused on optimization of the maximized fractionation of lignocellulosic materials for the utilization of EC in integrated biorefinery applications.

\section{Materials and methods}

\section{Materials}

Eucalyptus (EC) was collected from Mae Jan, Chiang Rai, Thailand. The raw material was dried at $70{ }^{\circ} \mathrm{C}$ for $24 \mathrm{~h}$ in a hot oven, cut using a Retsch ZM200 mill and sieved to a particle size of approximately $0.5-0.85 \mathrm{~cm}$. The final moisture content of the milled EC was $7 \%$, which was established by drying it in the oven at $105{ }^{\circ} \mathrm{C}$ to constant weight for $4 \mathrm{~h}$. The processed EC was stored in sealed plastic bags and kept at room temperature for further experimentation. The chemical composition of EC (cellulose, hemicellulose, lignin, and ash content) was analyzed using standard laboratory analytical procedures of the U.S. National Renewable Energy Laboratory (NREL) [8]. Briefly, a multiprocess analytical method was used to determine chemical compositions. The first step involved acid hydrolysis with $72 \%$ sulfuric acid for $60 \mathrm{~min}$ at $30{ }^{\circ} \mathrm{C}$. After that, an appropriate amount of DI water was added to dilute the concentration to $4 \%$. The slurry was sealed and placed in an autoclave at $121{ }^{\circ} \mathrm{C}$ for $1 \mathrm{~h}$ to complete the hydrolysis step. In the liquid phase, structural carbohydrates were quantified in the form of monomeric compounds. In the solid phase, the residue was placed in a muffle furnace at $575{ }^{\circ} \mathrm{C}$ for $24 \mathrm{~h}$, and then the portion of lignin and ash was calculated as the relative dried weight. In terms of chemical composition, EC was mainly composed of cellulose $(42.3 \%)$, hemicellulose $(20.3 \%)$, lignin $(32.1 \%)$, and $5.3 \%$ other components (e.g., ash and extractives).

\section{Solvothermal fractionation process for lignin extraction}

The clean fractionation process was performed in a $600 \mathrm{~mL}$ stainless-steel reactor. Subsequently, the reactor was heated in a temperature-controlled vertical shaking system to carry out optimal mixing and a thermocouple was used for internal temperature measurement (Parr Reactor 4560, Parr instrument, Moline, IL, USA). The initial standard reaction contained $10 \mathrm{~g}$ of EC in $150 \mathrm{~mL}$ of a ternary solvent mixed-phase system. The ternary mixture comprises methyl isobutyl ketone (MIBK), ethanol, and water $\left(35,25\right.$ and $40 \% \mathrm{v} / \mathrm{v}$, respectively). Sulfuric acid $\left(\mathrm{H}_{2} \mathrm{SO}_{4}\right)$ was selected as the homogeneous catalyst with a concentration of $0.020-0.040 \mathrm{M}$ and residue times were 30,60 or $90 \mathrm{~min}$. The reaction was heated to the desired temperature within the range $180-200{ }^{\circ} \mathrm{C}$, and the initial pressure was set to 25 bars under nitrogen gas $\left(\mathrm{N}_{2}\right)$. Inside the reactor, the mixture of solvents and biomass were stirred at $100 \mathrm{rpm}$ to retain the homogeneous catalyst of the system. After establishing the desired condition, the reactor was immersed in a water bath for $15 \mathrm{~min}$. The fractioned solid was separated from the liquid phase and washed with MIBK and DI water (1:2 v/v). The liquid phase was collected, combined with the rinsate and placed in a separatory funnel. In the aqueous-organic mixture, water was added until an aqueous-organic phase clearly separated. The chemical composition of isolated solid and native EC was determined using the NREL method. Cellulose yield, cellulose purity, hemicellulose removal, lignin removal, and lignin recovery were calculated using the following equations;

$$
\begin{aligned}
& \text { Cellulose yield }(\%)=\frac{(\text { cellulose remaining in solid pulp })}{(\text { cellulose content in raw corn stover })} \times 100 \\
& \text { Cellulose purity }(\%)=\frac{(\text { cellulose remaining in solid pulp })}{(\text { total content in solid pulp })} \times 100
\end{aligned}
$$




$$
\begin{aligned}
& \text { Hemicellulose removal }(\%)=\frac{\text { (hemicellulose content in raw corn stover) }-(\text { hemicellulose remaining in solid pulp) }}{\text { (hemicellulose content in raw corn stover) }} \times 100 \\
& \text { Lignin removal }(\%)=\frac{(\text { lignin content in raw corn stover) } \text { (lignin remaining in solid pulp) }}{\text { (lignin content in raw corn stover) }} \times 100 \\
& \text { Recovered lignin }(\%)=\frac{\text { (weight of recovered lignin from organic phase })}{\text { (lignin content in raw corn stover) }} \times 100
\end{aligned}
$$

Experimental design and optimum parameters for lignin recovery using response surface methodology (RSM)

Response surface methodology (RSM) and statistical analysis were chosen to identify the optimization parameters of 3 variables (i.e., concentration, temperature, and time) for cellulose yield, lignin removal, and lignin recovery. To estimate the model coefficients, 3 modified Box-Behnken designs were implemented (15 experiments). The 3 factors involve reaction concentration $\left(\mathrm{X}_{1}, 0.020-0.040 \mathrm{M}\right)$, reaction temperature $\left(\mathrm{X}_{2}, 180-200{ }^{\circ} \mathrm{C}\right)$, and residence time $\left(\mathrm{X}_{3}, 30\right.$ - $\left.90 \mathrm{~min}\right)$ with 3 coded levels for each factor $(-1,0,1)$. The variance in each assessed factor was partitioned into offset term, linear, interaction, and quadratic components, and all predictive parameters were written as the following second-order polynomial equation;

$Y=\beta_{0}+\beta_{1} X_{1}+\beta_{2} X_{2}+\beta_{3} X_{3}+\beta_{12} X_{1} X_{2}+\beta_{13} X_{1} X_{3}+\beta_{23} X_{2} X_{3}+\beta_{11} X^{2}{ }_{1}+\beta_{22} X_{2}^{2}+\beta_{33} X^{2}$

here, $Y$ is the predicted response; $X_{1}, X_{2}$, and $X_{3}$ are the independent variables; $\beta_{0}$ is a constant term; $\beta_{1}, \beta_{2}$, and $\beta_{3}$ are the linear coefficient terms; $\beta_{12}, \beta_{13}$, and $\beta_{23}$ are the interaction coefficients; and $\beta_{11}, \beta_{22}$, and $\beta_{33}$ are the quadratic coefficients. A fitted quadratic polynomial was used to generate $3 \mathrm{D}$ surface plots of the correlation between the independent variables and the response.

\section{Characterization of the solid residue after fractionation}

\section{$X$-ray diffraction (XRD analysis)}

Crystallinities of the native and isolated solid fractions were determined by X-ray diffraction (XRD) using an X'Pert PRO diffractometer (Panalytical, Almelo, Netherlands). The samples were scanned in the range of $2 \theta=10-30^{\circ}$ with a step size of $0.02^{\circ}$ at $500 \mathrm{kV}$ and $30 \mathrm{~mA}$ and with $\mathrm{Cu} \mathrm{K} \alpha$ radiation $(\lambda=1.54$ $\AA$ ). Crystallinity was calculated using the following equation;

$$
\mathrm{CrI}=\frac{\mathrm{I}_{002}-\mathrm{I}_{\text {amorphous }}}{\mathrm{I}_{002}} \times 100
$$

here, $\mathrm{I}_{002}$ is the intensity of the crystalline signal for biomass (i.e., cellulose) at $2 \theta=22.4$, and $\mathrm{I}_{\text {amorphous }}$ is the peak for the amorphous portion (i.e., cellulose, hemicellulose, and lignin) at $2 \theta=18.0$.

\section{Scanning electron microscopy (SEM)}

The microstructures of the native and isolated solids were analyzed using scanning electron microscopy (JSM-6301F, JEOL, and Japan) with an electron beam energy of $5-20 \mathrm{kV}$. The EC samples were dried and coated with gold before SEM analysis.

\section{Analysis of the aqueous phase}

The soluble product profiles in the aqueous fraction were analyzed with high-performance liquid chromatography (LDC Model 4100, Shimadzu, Kyoto, Japan) equipped with refractive index and UV-Vis detectors, and an Aminex HPX-87H column (Bio-Rad, Hercules, CA, USA). The oven operated at $65^{\circ} \mathrm{C}$, the mobile phase contained $5 \mathrm{mM} \mathrm{H}_{2} \mathrm{SO}_{4}$ and the flow rate was $0.5 \mathrm{~mL} / \mathrm{min}$. The number of oligosaccharides was determined according to the NREL method. 


\section{Characterization of lignin recovery after fractionation \\ Elemental compositions analysis}

The elemental compositions of commercial lignin and recovered lignin were determined using the elemental analyzer CHNS-628 (LECO, Saint Joseph, MI, USA). Commercial lignin and recovered lignin were dried at $60{ }^{\circ} \mathrm{C}$ in a vacuum evaporator with a pressure of 20 mbars to remove moisture. Subsequently, $0.1 \mathrm{~g}$ of commercial lignin or recovered lignin were encapsulated in the container to determine the carbon, hydrogen, and nitrogen contents in the sample. For sulfur analysis, $0.2 \mathrm{~g}$ of commercial lignin and lignin recovery was placed into a ceramic boat furnace. Incineration at $1,350{ }^{\circ} \mathrm{C}$ using sulfur IR cells was performed to detect the amount of sulfur.

\section{Fourier-transform infrared spectroscopy (FT-IR)}

The chemical structure of commercial lignin and lignin recovery was characterized using Fouriertransform infrared spectroscopy analysis (FTIR). Analysis was performed using an FTIR instrument (Perkin Elmer, Waltham, MA, USA), and samples were prepared using the KBr pellet method. The region between 4000 and $400 \mathrm{~cm}^{-1}$ was recorded with a resolution of $4 \mathrm{~cm}^{-1}$ and 32 scans. Peaks for lignin were compared with those of standard functional groups.

\section{Thermogravimetric analysis (TGA)}

The thermal stabilities of commercial lignin and recovered lignin were measured by heating specimens at a rate of $7{ }^{\circ} \mathrm{C}$ per min under a nitrogen gas flow of $20-35 \mathrm{~mL} / \mathrm{min}$. The weight of the specimen was monitored as a function of temperature using a TA Instruments Inc., Model TA Q50 system. Approximately 30 - $50 \mathrm{mg}$ of commercial lignin and recovered lignin were weighed in an aluminum pan and heated to a temperature of approximately $1,000{ }^{\circ} \mathrm{C}$ at a rate of $5{ }^{\circ} \mathrm{C} / \mathrm{min}$ to determine the total mass loss. A plot of weight-loss versus temperature was prepared from the data obtained. A derivative of this curve (DTG) was produced to indicate the temperatures at which maximum rates of weight loss occurred.

\section{Gel permeation chromatography (GPC)}

Precipitated samples of commercial lignin and recovered lignin were subjected to gel permeation chromatography (GPC) to determine average molecular weight $\left(M_{w}\right)$ and polydispersity indexes $\left(M_{w} / M_{n}\right)$ using a Jasco instrument equipped with an interface (LC-NetII/ADC) and a UV detector (254 $\mathrm{nm}$ ). In this process, $0.1 \mathrm{~g}$ of lignin was dissolved in tetrahydrofuran solution, tests conducted with 2 PolarGel-M803 columns $\left(300 \times 7.5 \mathrm{~mm}^{2}\right)$ and a PolarGel-M guard column $\left(50 \times 7.5 \mathrm{~mm}^{2}\right)$, and tetrahydrofuran (THF) was selected as the mobile phase. The flow rate was $0.5 \mathrm{~mL} / \mathrm{min}$, and the column temperature was $40{ }^{\circ} \mathrm{C}$. Calibration was performed using polystyrene standards (Sigma-Aldrich) with a range of 55,000-266 $\mathrm{g} / \mathrm{mol}$.

\section{Pyrolysis-gas chromatography-mass spectrometry (Py-GC/MS)}

Pyrolysis-GC/MS was used to characterize the chemical composition of the recovered lignin used in this study. Pyrolysis of the recovered lignin was performed at $500{ }^{\circ} \mathrm{C}$ in an EGA/PY-3030D microfurnace pyrolyzer (Frontier Laboratories Ltd., Fukushima, Japan) connected to a GC 7820A (Agilent Technologies, Inc., Santa Clara, CA) and an Agilent 5975 mass-selective detector (EI at $70 \mathrm{eV}$ ). The dimensions of the column used were $30 \mathrm{~m} \times 0.25 \mathrm{~mm}$ i.d., and it had a $0.25 \mu \mathrm{m}$ film thickness (DB-1701, $\mathrm{J} \& \mathrm{~W}$ Scientific, Folsom, CA). The oven temperature was increased from $50{ }^{\circ} \mathrm{C}(1 \mathrm{~min})$ to $100{ }^{\circ} \mathrm{C}$ at 20 ${ }^{\circ} \mathrm{C} \mathrm{min}{ }^{-1}$ and then to $280{ }^{\circ} \mathrm{C}(5 \mathrm{~min})$ at $6{ }^{\circ} \mathrm{C} \min ^{-1}$. Helium was the carrier gas $\left(1 \mathrm{~mL} \mathrm{~min}{ }^{-1}\right.$ flow rate). The released compounds were identified through comparison of their mass spectra with those of the Wiley and NIST libraries and those reported in the literature [9] and through comparison with the retention times and mass spectra of authentic standards, when possible. The molar peak area was calculated for each released lignin degradation product. The total areas were normalized, and the data for 2 replicates were averaged and expressed as percentages [10]. 
Table 1 Effect of reaction factors on the solid composition of the solvothermal fractionation process for isolated lignin using the response surface method (RSM).

\begin{tabular}{ccccccc}
\hline Run no. & T $\left({ }^{\circ} \mathbf{C}\right)$ & $\begin{array}{c}\text { Time } \\
(\mathbf{M i n})\end{array}$ & $\begin{array}{c}\text { Concentration } \\
(\mathbf{M})\end{array}$ & $\begin{array}{c}\text { Cellulose } \\
\text { Yield (\%) }\end{array}$ & $\begin{array}{c}\text { Responses (\%) } \\
\text { Lignin } \\
\text { Removal (\%) }\end{array}$ & $\begin{array}{c}\text { Lignin } \\
\text { recovery (\%) }\end{array}$ \\
\hline 1 & 190 & 60 & 0.03 & 91.20 & 77.30 & 73.40 \\
\hline 2 & 190 & 90 & 0.04 & 84.13 & 64.33 & 63.50 \\
\hline 3 & 200 & 60 & 0.02 & 90.13 & 83.00 & 78.60 \\
\hline 4 & 180 & 90 & 0.03 & 59.60 & 65.63 & 63.85 \\
\hline 5 & 190 & 30 & 0.04 & 73.88 & 87.63 & 84.50 \\
\hline 6 & 180 & 60 & 0.02 & 85.38 & 57.80 & 53.30 \\
\hline 7 & 190 & 30 & 0.02 & 90.48 & 84.40 & 81.20 \\
\hline 8 & 200 & 30 & 0.03 & 66.40 & 81.60 & 76.50 \\
\hline 9 & 190 & 60 & 0.03 & 90.50 & 76.60 & 72.40 \\
\hline 10 & 200 & 60 & 0.04 & 83.53 & 51.40 & 48.10 \\
\hline 11 & 190 & 60 & 0.03 & 90.50 & 76.60 & 74.50 \\
\hline 12 & 180 & 30 & 0.03 & 82.40 & 87.23 & 83.25 \\
\hline 13 & 200 & 90 & 0.03 & 88.55 & 77.88 & 75.75 \\
\hline 14 & 180 & 60 & 0.04 & 78.00 & 72.00 & 69.12 \\
\hline 15 & 190 & 90 & 0.02 & 80.91 & 84.65 & 80.70 \\
\hline
\end{tabular}

${ }^{\mathrm{a}}$ Based on the relative content of cellulose in the remaining pulp

${ }^{b}$ Based on the relative content of lignin in solid pulp compared with lignin content in raw material

${ }^{c}$ Based on the weight of lignin in the organic phase

\section{Results and discussion}

Chemical composition of the raw material and solid fractions from solvothermal fractionation

As reported, the chemical components of the raw eucalyptus (EC) residue include cellulose (35\%), hemicellulose $(20 \%)$, lignin (36\%), ash (5\%), and extractive (4\%), with all contents expressed as wt $\%$. Experimental optimization with 15 runs is shown in Table 1. The influence of the reaction factors concentration, temperature, and residence time on cellulose yield, lignin removal, and lignin recovery was investigated using response surface methodology (RSM). The results were found to lie in the ranges 59.6 - 91.2, $51.4-87.6$ and 48.1 - $84.5 \%$, respectively. The resulting optimization of the solvothermal fractionation process was analyzed using analysis of variance (ANOVA) and conditions of acid concentration $(0.020-0.040 \mathrm{M})$, temperature $\left(180-200{ }^{\circ} \mathrm{C}\right)$, and time $(30-90 \mathrm{~min})$ were chosen to maximize cellulose yield, lignin removal, and lignin recovery. The calculated regression equation for fractionation optimization highlighted cellulose yield $\left(\mathrm{Y}_{1}, \%\right)$, lignin removal $\left(\mathrm{Y}_{2}, \%\right)$, lignin recovery $\left(\mathrm{Y}_{3}, \%\right)$ and gave fractional weights to acid concentration $\left(\mathrm{X}_{1}, \mathrm{M}\right)$, reaction temperature $\left(\mathrm{X}_{2},{ }^{\circ} \mathrm{C}\right)$, and residue time $\left(\mathrm{X}_{3}, \mathrm{~min}\right)$. It was found that a second-order polynomial multiple regression equation represented cellulose yield, lignin removal, and lignin recovery, as in Eqs. (6) - (8).

Cellulose yield $(\%)=-2149-2190 X^{1}+25.70 X^{2}-6.385 X^{3}+8161 X^{2}{ }_{1}-0.07293 X_{2}^{2}-0.010225 X^{2}{ }_{3}$

$+1.94 \mathrm{X}_{12}+16.510 \mathrm{X}_{13}+0.037458 \mathrm{X}_{23}$

Lignin removal $(\%)=-2789+25086 \mathrm{X} 1+27.29 \mathrm{X} 2-3.473 \mathrm{X} 3-43073 \mathrm{X}^{2}{ }_{1}-0.06476 \mathrm{X}_{2}{ }_{2}$ $+0.008582 \mathrm{X}_{3}^{2}-114.50 \mathrm{X}_{12}-19.625 \mathrm{X}_{13}+0.014896 \mathrm{X}_{23}$

Lignin recovery $(\%)=-2992+25149 X^{1}+29.40 X^{2}-3.541 X^{3}-41329 X^{2}{ }_{1}-0.07020 X^{2}{ }_{2}$ $+0.009083 \mathrm{X}_{3}^{2}-115.80 \mathrm{X}_{12}-17.08 \mathrm{X}_{13}+0.01471 \mathrm{X}_{23}$ 
The predicted values of cellulose yield, lignin removal, and lignin recovery in pretreated EC showed that equations for cellulose yield, lignin removal, and lignin recovery were statistically significant at the $95 \%$ confidence interval for the optimization of EC fractionation, as the R-squared values of all responses were higher than 0.90 . In addition, the model accurately predicted cellulose yield (98.4 \%), lignin removal (98.8 \%), and lignin recovery (98.4\%) (Figures 1(A) - 1(C) and Table 2).
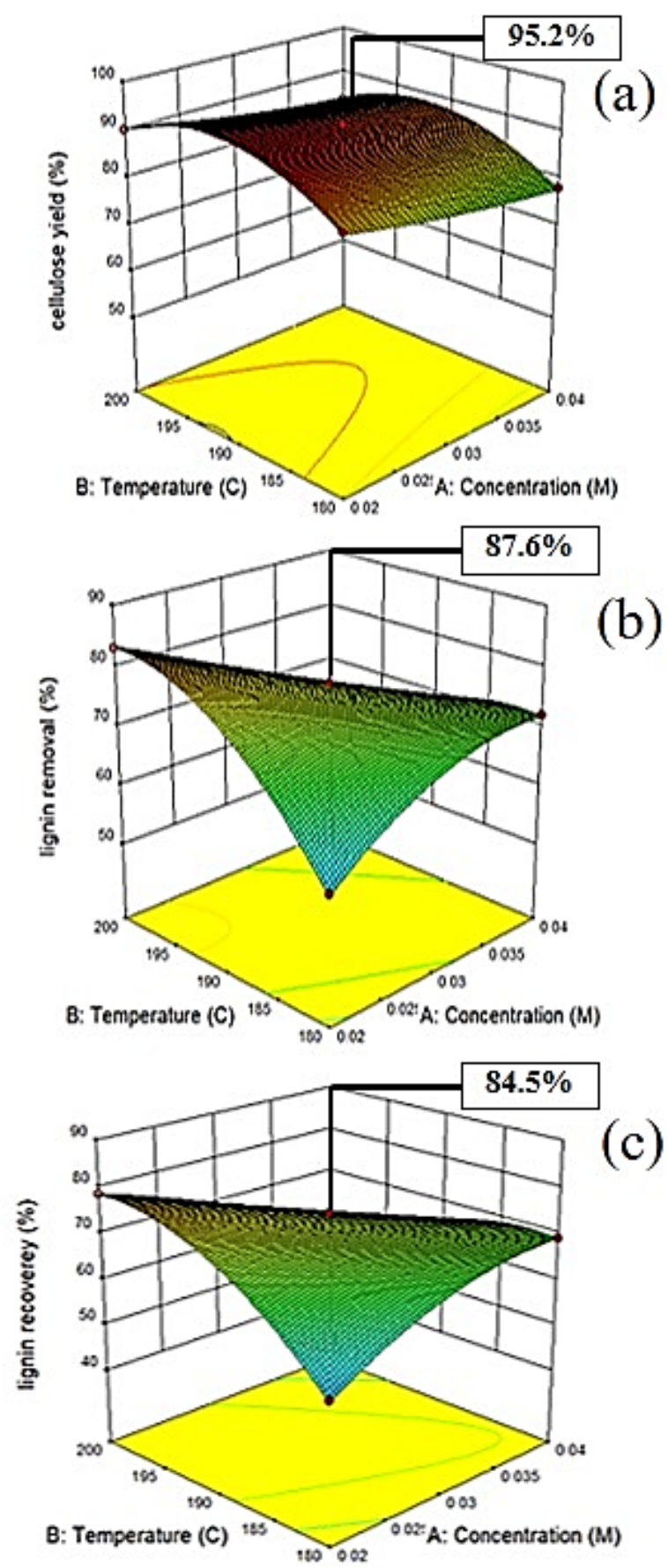

Figure 1 Response surface plot for the solvothermal fractionation process: (a) Effect of reaction concentration $(0.020-0.040 \mathrm{M})$ and temperature $\left(180-200{ }^{\circ} \mathrm{C}\right)$ on cellulose yield in the solid fraction with varying formic acid concentrations $(0.020 \mathrm{M})$; (b) Effect of reaction time $(30-90 \mathrm{~min})$ and temperature $\left(180-200^{\circ} \mathrm{C}\right)$ on lignin removal in the solid fraction with varying formic acid concentrations $(0.040 \mathrm{M})$; (c) Effect of reaction time $(30-90 \mathrm{~min})$ and temperature $\left(180-200{ }^{\circ} \mathrm{C}\right)$ on the amount of lignin recovered in the solid fraction with varying formic acid concentrations $(0.040 \mathrm{M})$. 
Table 2 Resultant regression models for responses based on ANOVA.

\begin{tabular}{llll}
\hline \multicolumn{1}{c}{ Source } & \multicolumn{3}{c}{ p-value $^{\mathbf{a}}$} \\
\cline { 2 - 4 } & Cellulose yield & Lignin removal & Lignin recovery \\
\hline $\begin{array}{l}\text { Model } \\
\text { Linear }\end{array}$ & & & \\
concentration & 0.0000 & 0.0000 & 0.0000 \\
temperature & 0.0000 & 0.0010 & 0.0070 \\
time & 0.9820 & 0.0000 & 0.0000 \\
Quadratic & & & 0.0000 \\
concentration* concentration & 0.0000 & 0.0000 & 0.0000 \\
temperature * temperature & 0.0350 & 0.0000 & 0.0000 \\
time*time & 0.0000 & 0.0000 & \\
2-Way Interaction & & & 0.0000 \\
concentration * temperature & 0.5090 & 0.0000 & 0.0000 \\
concentration *time & 0.0000 & 0.0000 & 0.0000 \\
temperature * time & 0.0000 & 0.0000 & \\
\hline
\end{tabular}

${ }^{a}$ Nonsignificant p-values are highlighted

\section{Optimization of cellulose yield, lignin removal, and lignin recovery from eucalyptus}

The model equations for all target responses (Eqs. (6) - (8)) showed the influences of acid concentration, reaction temperature, and residence time on cellulose yield, lignin removal, and lignin recovery in EC fractionation. The results indicated that the highest predicted cellulose yield of $95.63 \%$ would be obtained with $0.020 \mathrm{M}$ acid at a maximum temperature of $189.2929^{\circ} \mathrm{C}$ with a residence time of $50.6061 \mathrm{~min}$. Maximum lignin removal $(95.91 \%)$ and lignin recovery $(91.77 \%)$ were predicted for an acid concentration of $0.040 \mathrm{M}$ at $180{ }^{\circ} \mathrm{C}$ for $30 \mathrm{~min}$.

The best conditions, according to the optimization, would lead to cellulose yield $>90 \%$, lignin removal $>80 \%$, and lignin recovery $>80 \%$. However, in the regression analysis, these results were predicted for optimal conditions with an acid concentration of $0.040 \mathrm{M}$, a temperature of $180{ }^{\circ} \mathrm{C}$, and a residence time of $30 \mathrm{~min}$ with a solvent mixture of methyl isobutyl ketone (MIBK)/ethanol/water (35:25: $40 \mathrm{v} / \mathrm{v} \%)$. Under these conditions, the experimental studies provided the indicated results for maximum cellulose yield $(95.2 \%)$, lignin removal $(87.7 \%)$, and lignin recovery $(84.6 \%)$. It was found that the experimental results met the criteria under the optimal conditions.

\section{SEM and XRD characterization of native eucalyptus and solid remaining after solvothermal fractionation}

The microstructures of the native EC and solid isolated under the optimal conditions are shown in Figure 2. The surface of the native EC was smooth with embedded with matrix components of the material. The solid obtained under optimal conditions exhibited cavities and cracks on the surfaces due to the removal of lignin and modification of the hemicellulose structure, which resulted in modifications leading to enhancement of the available surface area for the internal cellulose structure [11].

In addition, the crystallinity indexes (CrI) of native EC and isolated solid were identified using Xray diffraction (XRD) techniques, and results are shown in Figure 3. According to analysis of the XRD diffraction patterns, $\mathrm{CrI}$ decreased to $62.8 \%$ in isolated solid from $74.3 \%$ in native EC. From these results, it can be seen that the decrease in CrI was due to elimination of hemicellulose and the external structure of lignin under the optimal conditions, resulting in a decrease in CrI. According to a previous study, sugarcane bagasse components were isolated during the organosolv process. The CrI of the solid isolated from fractionation exhibited a decrease in CrI $(67.09 \%)$ compared to that of native sugarcane bagasse (72.83 \%) [12]. Furthermore, a decrease in $\mathrm{CrI}$ after the fractionation process under the organosolv process was also seen. 


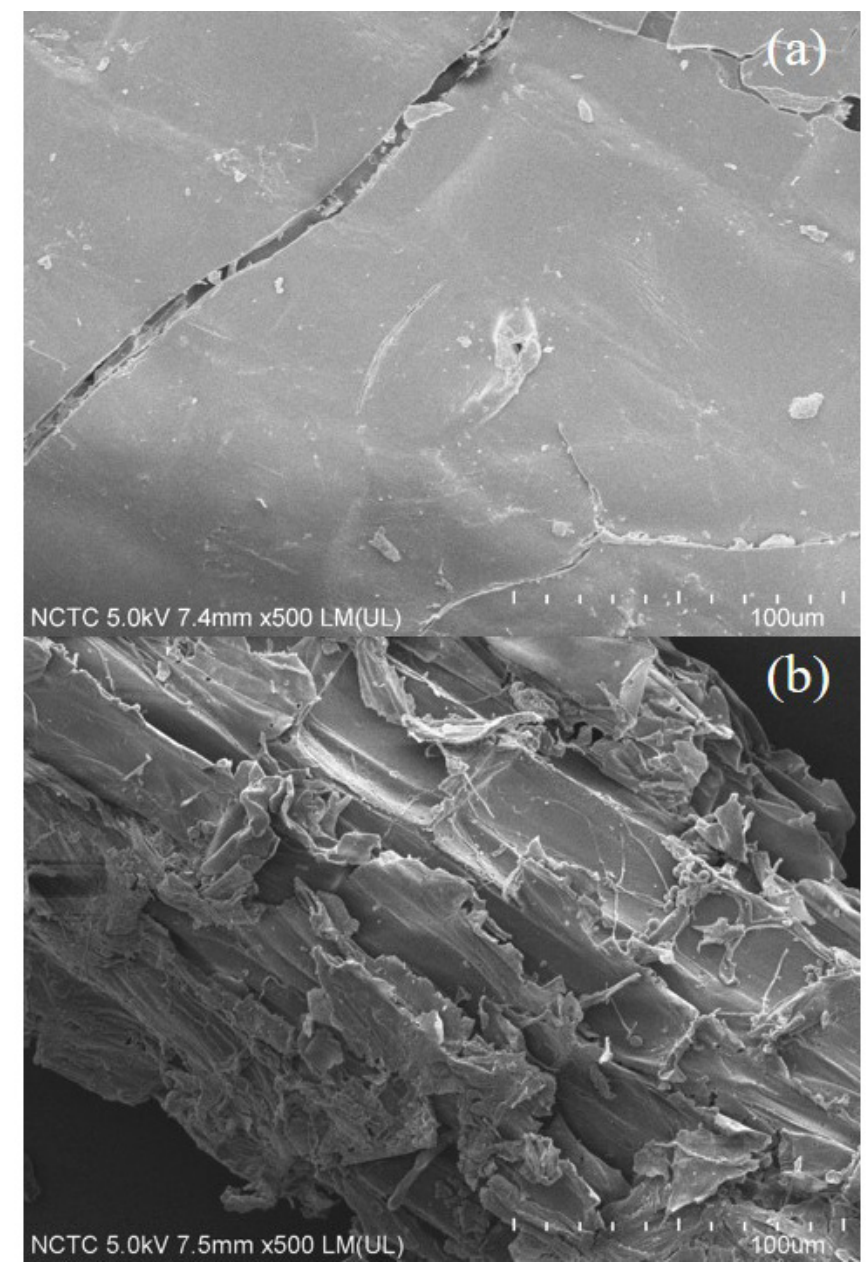

Figure 2 Scanning electron microscopy images of (a) native eucalyptus and (b) isolated solids after fractionation, which were obtained under optimal conditions involving a temperature of $180{ }^{\circ} \mathrm{C}$ and a 30 min residence time with a solvent mixture comprising MIBK/ethanol/water (35\%:25\%:40\% v/v\%).

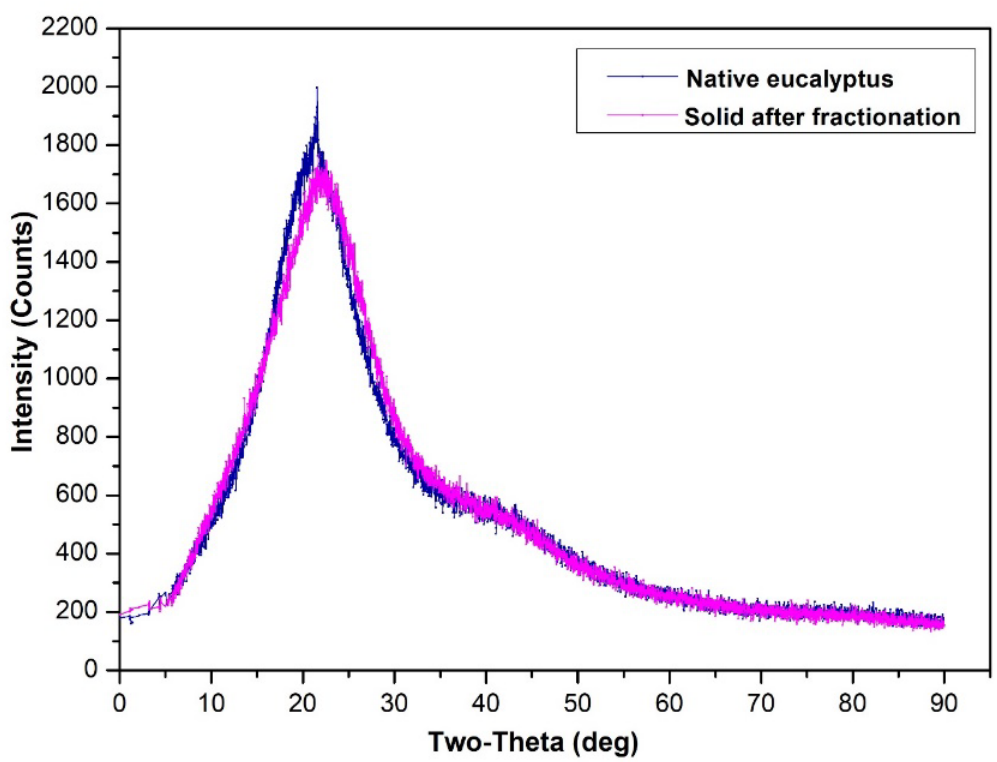

Figure 3 XRD analysis of native eucalyptus and isolated solids after fractionation. 
Characterization of lignin fraction by Fourier transform infrared spectroscopy (FTIR) analysis of recovered lignin and original lignin

Fourier-transform infrared (FTIR) spectroscopy analysis of the recovered lignin and original lignin is shown in Table 3. The results showed C-H stretches in the methyl absorption region $\left(2922 \mathrm{~cm}^{-1}\right)$ and those of methylene groups $\left(2850 \mathrm{~cm}^{-1}\right)$. The intense peak at $1720-1728 \mathrm{~cm}^{-1}$ was related to $\mathrm{C}=\mathrm{O}$ stretches of carbonyl groups, while the peak at 1600 was assigned to aromatic compounds (phenolic hydroxyl groups; $\mathrm{OH})$. The absorption at $1460-1500 \mathrm{~cm}^{-1}$ corresponds to aromatic groups, and the frequencies of aromatic skeleton vibration in combination with $\mathrm{C}-\mathrm{H}$ vibrations were found at $1422-1428$ $\mathrm{cm}^{-1}$. The peaks at $1332 \mathrm{~cm}^{-1}$ were found to represent of syringyl (S) units. The absorption peaks at 1221 and $1230 \mathrm{~cm}^{-1}$ were associated with $\mathrm{C}-\mathrm{O}$ and $\mathrm{C}=\mathrm{O}$ stretching vibrations of guaiacyl $(\mathrm{G})$ units. The peak at $1220 \mathrm{~cm}^{-1}$ corresponds to coniferyl aromatic rings, while the vibrations shown at $1120-1121 \mathrm{~cm}^{-1}$ were related to aromatic C-H groups. Similarly, bands occurring from 1031 to $1034 \mathrm{~cm}^{-1}$ were observed for aromatic $\mathrm{C}-\mathrm{H}$ groups of syringyl and $\mathrm{G}$ units. In addition, signals for $\mathrm{C}-\mathrm{H}$ and $\mathrm{CH}_{3}$ groups of $\mathrm{G}$ units were at 816 and $830 \mathrm{~cm}^{-1}$, respectively [13-15].

Table 3 Functional groups based on FTIR analysis of recovered lignin and commercial lignin under.

\begin{tabular}{|c|c|c|c|c|}
\hline Order & Commercial lignin & Lignin recovery & Bend & Functional group \\
\hline 1 & 2922 & 2922 & $\mathrm{C}-\mathrm{H}$ stretch & Methyl group \\
\hline 2 & 2850 & 2850 & $\mathrm{C}-\mathrm{H}$ stretch & Methylene groups \\
\hline 3 & 1720 & 1728 & $\mathrm{C}=\mathrm{O}$ stretching & Carbonyl groups \\
\hline 4 & 1600 & 1600 & $\mathrm{OH}$ stretch & Phenolic hydroxyl group \\
\hline 5 & 1461,1500 & 1460,1500 & Aromatic & $\begin{array}{l}\text { Aromatic carbon } \\
\text { atoms group }\end{array}$ \\
\hline 6 & 1422 & 1428 & $\begin{array}{l}\text { C-H stretch in } \\
(\mathrm{G}, \mathrm{S})\end{array}$ & Aromatic skeleton \\
\hline 7 & 1332 & 1332 & $\mathrm{C}-\mathrm{H}$ deformation & Syringyl (S) units \\
\hline 8 & 1230 & 1221 & $\begin{array}{c}\mathrm{C}-\mathrm{O} \text { stretch and } \mathrm{C}=\mathrm{O} \\
\text { vibrations }\end{array}$ & Guaiacyl (G) units \\
\hline 9 & 1220 & - & $\mathrm{C}-\mathrm{O}$ vibrations & $\begin{array}{c}\text { Coniferyl } \\
\text { aromatic rings }\end{array}$ \\
\hline 10 & 1120 & 1121 & $\mathrm{C}-\mathrm{H}$ & Aromatic C-H group \\
\hline 11 & 1031 & 1034 & aromatic C-H & $\begin{array}{l}\text { Synapyl and } \\
\text { Guaiacyl unit }\end{array}$ \\
\hline 12 & 816 & 830 & $\mathrm{C}-\mathrm{H}$ and $\mathrm{C}-\mathrm{H}_{3}$ groups & Guaiacyl unit \\
\hline
\end{tabular}

Molecular weight analysis of recovered lignin and original lignin

Molecular weight analyses for recovered lignin and commercial lignin are shown in Table 4. The weight average molecular weights $\left(M_{w}\right)$, number average molecular weights $\left(M_{n}\right)$ and polydispersity indexes (PDI) were determined using gel permeation chromatography (GPC). The results showed that the molecular weight of recovered lignin under the optimal conditions exhibited a lower average $M_{w}$ and $M_{n}$ than commercial lignin. The $\mathrm{M}_{\mathrm{w}}$ values of recovered lignin and commercial lignin were $20,812 \mathrm{~g} / \mathrm{mol}$ and $21,200 \mathrm{~g} / \mathrm{mol}$, respectively. The PDIs of recovered lignin and commercial lignin were 2.19 and 2.46, respectively. These result indicate similar particle sizes for the recovered lignin before and after the fractionation process. As previously reported, lignin isolated from EC with an alkali-acid purification process using a ternary mixture solvent of MIBK/methanol/water for organosolv fractionation exhibited PDI values for the extracted lignin of $2.0-2.10 \mathrm{~g} / \mathrm{mol}$, which was not significantly different from the results of this study [16]. 
Table 4 Weight-average molecular weight $(\mathrm{Mw})$ of recovered lignin and commercial lignin.

\begin{tabular}{ccccc}
\hline & Sample name & $\mathbf{M w}^{\mathbf{a}}(\mathbf{g} / \mathbf{m o l})$ & $\mathbf{M n}^{\mathbf{b}}(\mathbf{g} / \mathbf{m o l})$ & $\mathbf{M w} / \mathbf{M n}(\mathbf{P D I})^{\mathbf{c}}$ \\
\hline 1 & Lignin recovery & 20812 & 9500 & 2.19 \\
\hline 2 & Commercial lignin & 21200 & 8600 & 2.46 \\
\hline
\end{tabular}

${ }^{\mathrm{a}}$ Weight-average molecular weight $(\mathrm{Mw})$

${ }^{\mathrm{b}}$ Number-average molecular weight $(\mathrm{Mn})$

${ }^{c}$ Polydispersity index (PDI)

Table 5 Elemental analysis of recovered lignin and commercial lignin.

\begin{tabular}{cccccccccc}
\hline & \multicolumn{1}{c}{ Proximate analysis $(\mathbf{w t} \% \mathbf{d . b} \%)$} & \multicolumn{5}{c}{ Elemental analysis } \\
\hline Sample & $\begin{array}{c}\text { Volatile } \\
\text { materials } \\
(\mathbf{d . b} \%)\end{array}$ & $\begin{array}{c}\text { Fixed } \\
\mathbf{c a r b o n} \\
(\mathbf{d . b} \%)\end{array}$ & $\begin{array}{c}\text { Moisture } \\
\mathbf{( \% )}\end{array}$ & $\begin{array}{c}\text { Ash } \\
(\mathbf{d . b} \%)\end{array}$ & $\mathbf{C}$ & $\mathbf{H}$ & $\mathbf{O}$ & $\mathbf{N}$ & $\mathbf{S}$ \\
\hline Lignin recovery & 68.2 & 29.9 & 0.3 & 1.6 & 61.3 & 5.50 & 30.1 & 0.01 & 1.2 \\
\hline $\begin{array}{c}\text { Commercial } \\
\text { lignin }\end{array}$ & 62.5 & 36.8 & 0.20 & 0.5 & 60.9 & 5.78 & 29.8 & 0.04 & 0.78 \\
\hline
\end{tabular}

Effect on proximate analysis and elementals composition

The proximate analysis of recovered lignin and commercial lignin obtained under the optimal conditions is shown in Table 5. The results showed that the proximate analysis of recovered lignin mainly indicated volatile materials with abundances in the range of $62.5-68.2 \mathrm{wt} \%$, fixed carbon in the range of $29.9-36.8 \mathrm{wt} \%$, moisture in the range of $0.2-0.3 \mathrm{wt} \%$, and ash in the range of $0.5-1.7 \mathrm{wt} \%$. However, recovered lignin showed a higher ash content than commercial lignin, as a high amount of sulfur was used in the catalyst for the solvothermal fractionation process [17]. In addition, the elemental content of recovered lignin and commercial lignin showed that the sulfur content in the recovered lignin was $1.2 \%$ based on dry weight, which is slightly higher than that of commercial lignin $(0.78 \%)$ due to the use of concentrated sulfuric acid $\left(\mathrm{H}_{2} \mathrm{SO}_{4}\right)$ as the catalyst in the EC fractionation process [16].

\section{Thermal decomposition of recovered lignin and commercial lignin}

Lignin thermal stability was determined using thermogravimetric analysis (TGA) (Figure 4). Lignin decomposition occurred in 3 stages. The first stage was observed at low temperatures ranging from 50 to $\sim 150{ }^{\circ} \mathrm{C}$, which corresponds to the loss of water [18]. The second decomposition stage occurred in the high-temperature range $160-400{ }^{\circ} \mathrm{C}$ and was due to the decompositions involving volatile substances, degradation of $\beta-\mathrm{O}-4, \alpha-\mathrm{O}-4$ bonds, phenolic hydroxyl linkages, and organic products including $\mathrm{CO}, \mathrm{CH}_{4}$, and $\mathrm{OH}$ groups [19]. In this stage, the maximum decomposition rates for recovered lignin and commercial lignin occurred at temperatures of 350 and $365^{\circ} \mathrm{C}$, respectively. This indicates that aliphatic side chains might break down and split from aromatic rings with the loss of $\mathrm{C}-\mathrm{C}$ linkages, inter-unit $\beta-\mathrm{O}-4$ linkages (the most abundant type), and $\beta-\beta$ and $\beta-5$ lignin bonds [20,21]. In the final stage, at temperatures in the range $400-550{ }^{\circ} \mathrm{C}$, the pyrolytic degradation of lignin, and decomposition and condensation of aromatic rings occurred [22].

\section{Pyrolysis-GCMS of recovered lignin and commercial lignin}

The identities and relative molar abundances of the commercial lignin and lignin-derived compounds released with relative abundance from the $\mathrm{H}, \mathrm{G}$, and $\mathrm{S}$-lignin units and the $\mathrm{S} / \mathrm{G}$ ratio were determined using pyrolysis gas chromatography-mass spectrometry (Py-GCMS) (Table 6). These results showed that commercial lignin contains S-units almost exclusively, with only small numbers of G-units and $\mathrm{H}$-units. $\mathrm{S} / \mathrm{G}$ ratios of 1.93 and 1.75 were obtained for commercial lignin and recovered lignin, respectively. The pyrograms highlighted the compounds derived from the syringyl (S), guaiacyl (G), and p-hydroxyphenyl (H) lignin units, with guaiacol (1), phenol (2), 4-methylphenol (4), 4-methylguaiacol (5), 4-ethylguaiacol (6), 4-vinylguaiacol (8), syringol (12), cis-isoeugenol (13), 4-methylsyringol (16), 4- 
vinylsyringol (22), and trans-propenylsyringol (27) showing high abundances; compounds such as phenol (2), 2-methylphenol (3), and 4-methylphenol (4), could be detected after the pyrolysis of the youngest wood (alfalfa and bromegrass). Moreover, some of these compounds can also be derived from abundant phenolic compounds. However, a significant number of compounds were derived from H-lignin units, other polysaccharides, such as hemicellulose and cellulose [23].
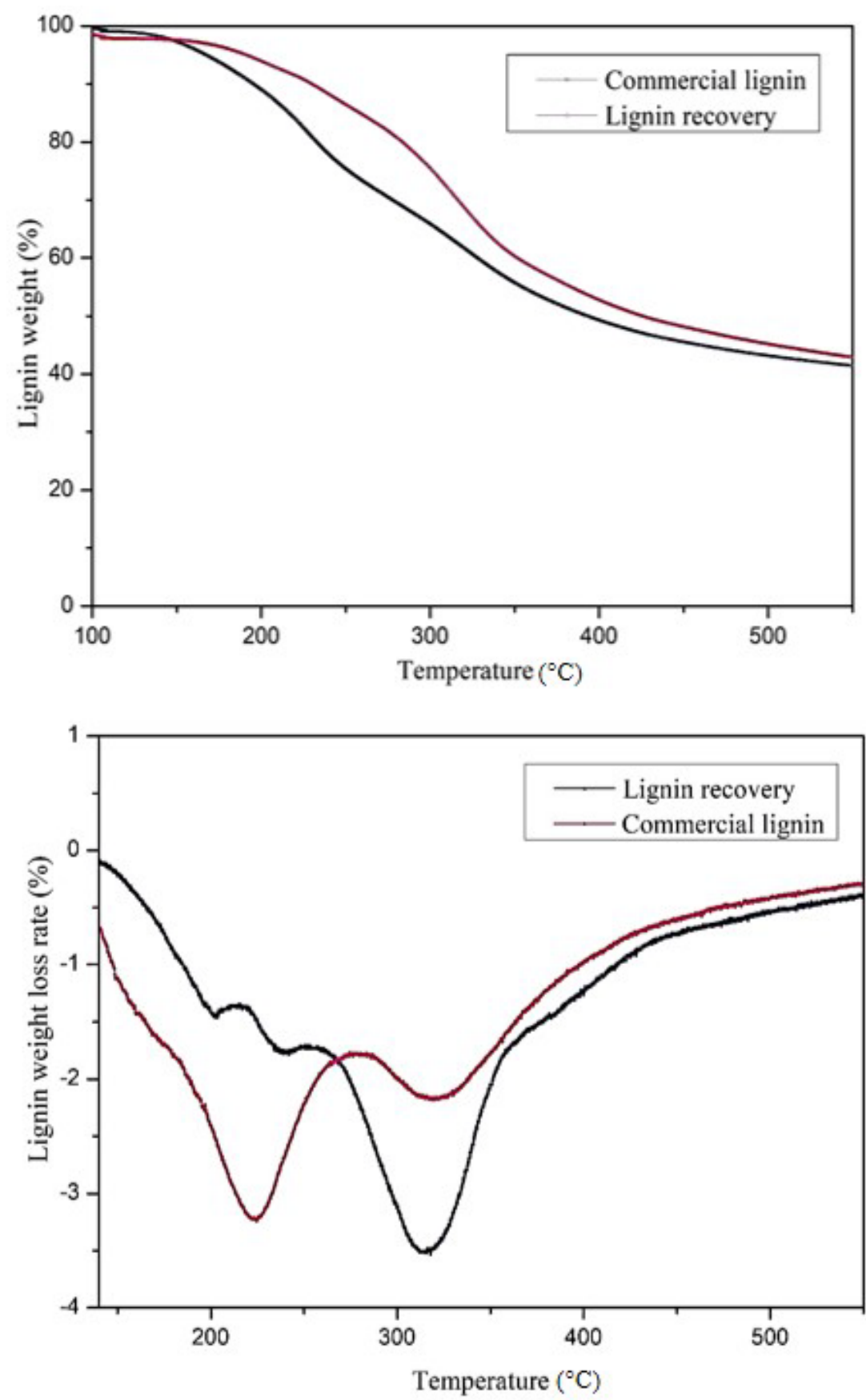

Figure 4 Thermal decomposition of recovered lignin and commercial lignin. 
Table 6 Results of Py-GCMS analysis for the identification of commercial lignin and recovered lignin and relative molar abundances $(\%)$.

\begin{tabular}{|c|c|c|c|c|}
\hline \multirow[b]{2}{*}{ No. } & \multirow[b]{2}{*}{ Compound } & \multirow[b]{2}{*}{ Origin } & \multicolumn{2}{|c|}{ relative molar abundance $(\%)$} \\
\hline & & & Commercial lignin & $\begin{array}{l}\text { Lignin recovery } \\
\text { (This study) }\end{array}$ \\
\hline 1 & Guaiacol & $\mathrm{G}$ & 2.2 & 2.3 \\
\hline 2 & Phenol & $\mathrm{H}$ & 7.5 & 7.2 \\
\hline 3 & 2-Methylphenol & $\mathrm{H}$ & 0.6 & 0.5 \\
\hline 4 & 4-Methylphenol & $\mathrm{H}$ & 2 & 2.1 \\
\hline 5 & 4-Methylguaiacol & $\mathrm{G}$ & 2.9 & 4.4 \\
\hline 6 & 4-Ethylguaiacol & $\mathrm{G}$ & 3.2 & 3.3 \\
\hline 7 & 4-Vinylphenol & $\mathrm{G}$ & 1.7 & 2.1 \\
\hline 8 & 4-Vinylguaiacol & $\mathrm{G}$ & 8.9 & 8.72 \\
\hline 9 & Guaiacyl vinyl ketone & $\mathrm{G}$ & 0.1 & 0.3 \\
\hline 10 & Eugenol & $\mathrm{G}$ & 0.8 & 0.6 \\
\hline 11 & 4-Propylguaiacol & $\mathrm{G}$ & 0.1 & 0.4 \\
\hline 12 & Syringol & $\mathrm{S}$ & 26.5 & 25.4 \\
\hline 13 & cis-Isoeugenol & $\mathrm{G}$ & 2.24 & 1.86 \\
\hline 14 & Syringic acid methyl ester & $\mathrm{S}$ & 0.5 & 0.4 \\
\hline 15 & trans-Isoeugenol & $\mathrm{G}$ & 1.88 & 0.47 \\
\hline 16 & 4-Methylsyringol & $\mathrm{S}$ & 4.2 & 8 \\
\hline 17 & Vanillin & $\mathrm{G}$ & 0.7 & 2.5 \\
\hline 18 & Homovanillin & $\mathrm{G}$ & 0.1 & 1.35 \\
\hline 19 & 4-Ethylsyringol & $\mathrm{S}$ & 2.8 & 3 \\
\hline 20 & 4-Allylguaiacol & $\mathrm{G}$ & 1.8 & 1.3 \\
\hline 21 & Acetovanillone & $\mathrm{G}$ & 0.9 & 1.4 \\
\hline 22 & 4-Vinylsyringol & $\mathrm{S}$ & 8.58 & 8.8 \\
\hline 23 & Guaiacylacetone & $\mathrm{G}$ & 0.9 & 1 \\
\hline 24 & 4-Allylsyringol & $\mathrm{S}$ & 2.1 & 0.6 \\
\hline 25 & 4-Propylsyringol & $\mathrm{S}$ & 0.7 & 0.5 \\
\hline 26 & cis-Propenylsyringol & $\mathrm{S}$ & 1.8 & 1.4 \\
\hline 27 & trans-Propenylsyringol & $\mathrm{S}$ & 4.7 & 3 \\
\hline 28 & Syringaldehyde & $\mathrm{S}$ & 1.6 & 4.5 \\
\hline 29 & Dihydroconiferyl alcohol & $\mathrm{G}$ & 0.1 & 0.3 \\
\hline 30 & Homosyringaldehyde & $\mathrm{S}$ & 0 & 0.3 \\
\hline 31 & Syringyl-3-oxo-propanal & $\mathrm{S}$ & 0 & 0.8 \\
\hline 32 & Acetosyringone & $\mathrm{S}$ & 1.5 & 2.8 \\
\hline 33 & trans-Coniferyl alcohol & $\mathrm{G}$ & 2 & 0 \\
\hline 34 & Coniferaldehyde & $\mathrm{G}$ & 0.2 & 0.5 \\
\hline 35 & Syringylacetone & $\mathrm{S}$ & 2.4 & 2.3 \\
\hline 36 & Propiosyringone & $\mathrm{S}$ & 0.2 & 0.5 \\
\hline 37 & Syringyl vinyl ketone & $\mathrm{S}$ & 0.2 & 0.6 \\
\hline 38 & Syringic acid & $\mathrm{S}$ & 0.2 & 0.9 \\
\hline 39 & trans-Sinapyl alcohol & $\mathrm{S}$ & 1.2 & 1 \\
\hline \multirow[t]{6}{*}{40} & trans-Sinapaldehyde & $\mathrm{S}$ & 0 & 0.6 \\
\hline & Total H (\%) & & 10.1 & 9.8 \\
\hline & Total G (\%) & & 30.72 & 32.8 \\
\hline & Total S (\%) & & 59.18 & 57.4 \\
\hline & $\mathrm{S} / \mathrm{G}$ ratio & & 1.93 & 1.75 \\
\hline & Total $(\mathrm{H}, \mathrm{G}, \mathrm{S})$ & & 100 & 100 \\
\hline
\end{tabular}




\section{Conclusions}

This study was aimed at determining the optimal conditions for a modified solvothermal fractionation (SF) process converting lignocellulosic eucalyptus (EC) into chemicals and value-added products. A modified single-step organosolv fractionation method was investigated for fractionation of lignin from EC using mean optimum conditions for the solvothermal fractionation process that would enhance lignin removal $(87.7 \%)$ from the solid phase. The optimal conditions for lignin recovery in the organic phase involved $0.035 \mathrm{M}$ sulfuric acid, a reaction temperature of $180{ }^{\circ} \mathrm{C}$, a residence time of $40 \mathrm{~min}$ and the use of a mixed solvent comprising methyl isobutyl ketone (MIBK):ethanol:water (35:25:40 v/v\%); these conditions resulted in a lignin recovery efficiency of $84.6 \%$, indicating the efficacy of the conditions. While the cellulose yield and hemicellulose removal yield were both $>90 \%$, thermal degradation analysis showed that the maximum decomposition of recovered lignin resulted from the degradation of $\beta-\mathrm{O}-4, \alpha-\mathrm{O}-4$, phenolic hydroxyl linkages and loss of $\mathrm{CO}, \mathrm{CH}_{4}, \mathrm{OH}$ groups at temperatures within the range $160-400{ }^{\circ} \mathrm{C}$, indicating a low molecular weight for recovered lignin.

\section{Acknowledgements}

This project was financially supported by a research grant (RTA 6280003) from the Thailand Research Fund. Saksit Imman were supported by the Unit of Excellence (FF65-UoE008) and (FF65RIM001) from the University of Phayao, Thailand.

\section{References}

[1] R Ahorsu, F Medina and M Constantí. Significance and challenges of biomass as a suitable feedstock for bioenergy and biochemical production: A review. Energies 2018; 11, 3366.

[2] A Kupczyk, J Mączyńska, G Redlarski, K Tucki, A Bączyk and D Rutkowski. Selected aspects of biofuels market and the electromobility development in Poland: Current trends and forecasting changes. Appl. Sci. 2019; 9, 254.

[3] TB Rawal, M Zahran, B Dhital, O Akbilgic and L Petridis. The relation between lignin sequence and its 3D structure. Biochim. Biophys. Acta Gen. Subj. 2020; 1864, 129-547.

[4] B Bujanovic, R Sally, R Richard, H Kolby and R Atalla. Polyoxometalates in oxidative delignification of chemical pulps: Effect on lignin. Materials 2010; 3, 1888-903.

[5] RJA Gosselink. 2011, Lignin as a renewable aromatic resource for the chemical industry. Ph. D. Dissertation. Wageningen University, Wageningen, Netherlands.

[6] T Klamrassamee, T Tana, N Laosiripojana, L Moghaddam, Z Zhang, J Rencoret, A Gutierrez, JCD Rio and WOS Doherty. Effects of an alkali-acid purification process on the characteristics of eucalyptus lignin fractionated from a MIBK-based organosolv process. $R S C A d v .2016$; 6, 9263847.

[7] C Inkrod, V Champreda, M Raita and N Laosiripojana. Characteristics of lignin extracted from different lignocellulosic materials via organosolv fractionation. BioEnerg. Res. 2018; 11, 277-90.

[8] A Sluiter, B Hames, R Ruiz, C Scarlata, J Sluiter, D Templeton and D Crocker. Determination of structural carbohydrates and lignin in biomass. National Renewable Energy Laboratory, Colorado, 2008.

[9] P Chen, Q Zhang, R Shu, Y Xu, L Ma and T Wang. Catalytic depolymerization of the hydrolyzed lignin over mesoporous catalysts. Bioresour. Tech. 2017; 226, 125-31.

[10] W Wanmolee, N Laosiripojana, P Daorattanachai, L Moghaddam, J Rencoret, JCD Río and WOS Doherty. catalytic conversion of organosolv lignins to phenolic monomers in different organic solvents and effect of operating conditions on yield with methyl isobutyl ketone. ACS Sustain. Chem. Eng. 2018; 6, 3010-8.

[11] C Li, X Zhao, A Wang, GW Huber and T Zhang. Catalytic transformation of lignin for the production of chemicals and fuels. Chem. Rev. 2015; 115, 11559-624.

[12] N Suriyachai, N Kraikul, W Techanan and N Laosiripojana. Fractionation of lignocellulosic biopolymers from sugarcane bagasse using formic acid-catalyzed organosolv process. 3 Biotech $2018 ; 8,221$.

[13] TDM Florian, N Villani, M Aguedo, N Jacquet, HG Thomas, P Gerin and A Richel. Chemical composition analysis and structural features of banana rachis lignin extracted by two organosolv methods. Ind. Crops Prod. 2019; 132, 269-74. 
[14] SE Klein, J Rumpf, P Kusch, R Albach, M Rehahn, S Witzleben and M Schulze. Unmodified kraft lignin isolated at room temperature from aqueous solution for preparation of highly flexible transparent polyurethane coatings. RSC Adv. 2018; 8, 40765-77.

[15] D Watkins, M Nuruddin, M Hosur, A Tcherbi-Narteh and S Jeelani. Extraction and characterization of lignin from different biomass resources. J. Mater. Res. Tech. 2015; 4, $26-32$.

[16] T Klamrassamee, T Tana, N Laosiripojana, L Moghaddam, Z Zhang, J Rencoret and WOS Doherty. Effects of an alkali-acid purification process on the characteristics of eucalyptus lignin fractionated from a MIBK-based organosolv process. RSC Adv. 2016; 6, 92638-47.

[17] J Sameni, S Krigstin, DDS Rosa, A Lea and M Sain. Thermal characteristics of lignin residue from industrial processes. Bioresources 2014; 9, 725-37.

[18] A Ház, M Jablonský, I Šurina, F Kačík, T Bubeníková and J Ďurkovič. Chemical composition and thermal behavior of kraft lignins. Forests 2019; 10, 483.

[19] MB Vasile. Thermal degradation of lignin. Cellulose Chem. Tech. 2010; 44, 353-63.

[20] B Lin, R Li, R Shu, C Wang, Z Cheng and Y Chen. Hydrogenolysis and hydrodeoxygenation of lignin in a two-step process to produce hydrocarbons and alkylphenols. J. Energ. Inst. 2019; 92 , 784-91.

[21] CL Waters, RR Janupala, RG Mallinson and LL Lobban. Staged thermal fractionation for segregation of lignin and cellulose pyrolysis products: An experimental study of residence time and temperature effects. J. Anal. Appl. Pyrol. 2017; 126, 380-9.

[22] S Chu, AV Subrahmanyam and GW Huber. The pyrolysis chemistry of a $\beta-\mathrm{O}-4$ type oligomeric lignin model compound. Green Chem. 2013; 15, 125-36.

[23] J Ralph, K Lundquist, G Brunow, F Lu, H Kim, PF Schatz and W Boerjan. Lignins: Natural polymers from oxidative coupling of 4-hydroxyphenyl- propanoids. Phytochem. Rev. 2004; 3, 2960 . 